\title{
Long-run profits in times of crisis: A comparison between European SMEs and large companies*
}

\author{
Beneficios a largo plazo en tiempos de crisis: Una comparación entre PYME \\ y grandes empresas europeas
}

\author{
Nuria Alcalde-Fradejas** \\ MARISA RAMÍREZ-ALESÓN***
}

\begin{abstract}
This is pioneering research in that it makes a comparison of the process of convergence of long-run profits in the manufacturing sector of six European countries (2000-12), differentiating between SMEs and large firms, and by identifying the impact of the crisis on this process. The results obtained by employing the convergence model, known as the Partial Adjustment Model, indicate that the inter-country competitive process, is working better among large companies than among SMEs. The impact of the crisis on this process has been uneven across the countries and the sizes of the firms.
\end{abstract}

Key words: Convergence, crisis, Europe, firm, SME.

JEL Classification: F20, L60.

\section{Resumen}

Este trabajo es pionero al realizar una comparación del proceso de convergencia de los beneficios a largo plazo en el sector de manufacturas de seis países europeos (2000-12), diferenciando entre PYME y grandes empresas; $e$ identificando el impacto que tiene la crisis en este proceso.

* This study was supported by the MICINN-FEDER under Grant ECO2012-36290-C03-01 and the COMPETE Research Group. We would like to thank the anonymous reviewers and the Editor for their insightful comments, which have significantly improved our manuscript.

** Departamento de Dirección y Organización de Empresas. Universidad de Zaragoza (Spain). C/Gran Vía 2, 50006-Zaragoza (Spain). Telephone: + 34976762786.

E-mail: nuria.alcalde@unizar.es

*** Departamento de Dirección y Organización de Empresas. Universidad de Zaragoza (Spain). C/Gran Vía 2, 50006-Zaragoza (Spain). Telephone: + 34976762716.

E-mail: mramirez@unizar.es 
Los resultados obtenidos utilizando el modelo de convergencia Partial Adjusted Model indican que el proceso competitivo interpaís funciona mejor entre las grandes empresas que entre las PYME. El impacto de la crisis en este proceso ha sido desigual entre los países analizados y los tamaños de empresa.

Palabras clave: Convergencia, crisis, Europa, empresa, PYME.

Clasificación JEL: F20, L60.

\section{INTRODUCTION}

In recent years, the uncertainty and instability caused by the current economic crisis has affected businesses. The contraction of international demand and increased global competitive pressures have meant that both small and mediumsized companies (SMEs), and large firms face greater difficulties in sustaining their profit levels and surviving in a hostile environment such as the current one.

This situation is accentuated for the member countries of the European Union (EU) for two reasons. First, because the current economic crisis is affecting the more developed countries the hardest, and second, because these countries form part of the Common Market. The European Union is grounded on three main pillars: cohesion, integration and convergence among its members (Archibugi and Filippetti, 2011), therefore their governments are unable to establish entrance barriers to protect their businesses from increased competition.

Economic theory and industrial economics predict that, as a result of the competitive process and the mobility of firms and capital, national economies would homogenize and long-run profits could be expected to converge across economies, unless some types of barriers were established that would be insurmountable for potential competitors. Therefore, it would be expected that in the long-run a process of European integration would derive in a convergence result that is homogenous for all companies that form part of the same economic bloc.

The process of profit convergence among corporations of the European Union member countries has been the object of study in numerous articles, analyzing both specific economies (e.g. Goddard and Wilson, 1996 for the United Kingdom; Schohl, 1990 for Germany; Jenny and Weber, 1990 for France; Espitia and Salas, 1989 for Spain, among others) and combinations of several of them (e.g. Geroski and Jacquemin, 1988; Leonardi, 1995; Eklund and Wiberg, 2007; Goddard et al., 2005; Hirsch and Gschwandtner 2013). However, none of these articles have studied whether the convergence value of the long-run profits, and the pace at which this process occurs, could differ depending on the size of the companies. In Europe, $99.8 \%$ of companies are SMEs (European Commission, 2012) and their importance resides not only in their number, but also in the employment and value added that they create. However, there are significant differences in the characteristics of small, medium and large companies that could justify variations in the evolution of their respective results over time. 
Taking this into account, this study pursues two objectives that have not been analyzed to date. On one hand, we make a comparison of the convergence process of long-run profits differentiating between SMEs and large European companies; on the other, we analyze the impact of the current financial crisis on the process of convergence of business results.

To date there are no known studies that analyze the convergence process for the European Union, nor for any other economy, that differentiate firms by size. Although in recent years some research has been published that analyzes the impact of the economic crisis on the process of convergence in Europe, it has focused on the results of specific areas of the companies, such as innovation (e.g. Archibugi and Filippetti, 2011).

The results suggest that the inter-country competitive process, although far from being perfect, works better among the large corporations than the SMEs of the different countries. However, taking into account the limitations arising from the short period of time analyzed, the analysis does not suggest a substantial change, as a consequence of the crisis, in the models that explain the process of long term convergence.

The following section presents the research sample used to achieve the objectives proposed for the study. The sample was obtained from the database of the European Committee of Central Balance Sheet Data Offices (BACH / ESD, 2013) and encompasses six European countries for the period 2000-12. The third section performs an analysis of the evolution of corporate profitability and its components, differentiating by firm size. The fourth section presents the design of the research to achieve the proposed objectives. The primary results are then presented. Finally, the last section presents the main conclusions, implications and limitations of the research.

\section{Source Of Information And The Presentation Of The Samples}

In order to achieve the stated objectives, the new Bank for the Accounts of Companies Harmonized-BACH-Database ${ }^{1}$ is used. As the 2013 Bach Summary Userguide states, this database is the result of the merger of two databases. The first is the original BACH project launched in 1985 by the General Directorate for Economic and Financial Affairs of the European Commission that provides a database with aggregated and harmonized annual accounting data and analyzes the financial structures and performance of non- financial European companies. The second is the European Sectoral References Database-ESD-created in the late nineties to provide financial ratios of non-financial corporations.

1 BACH-ESD Database: Banco de España, Banco de Portugal, Banque de France, National Bank of Belgium, National Bank of Poland, Centraal Bureau voor de Statistiek (the Netherlands), Centrale dei Bilanci - Cerved srl, Deutsche Bundesbank, Oesterreichische Nationalbank 
Accounts are "harmonized" through the use of common layouts for balance sheets, profit and loss statements, statements of investments and statements of depreciation. The main goal of the harmonization work of the Directorate General for Economic and Financial Affairs and ECCB has been to achieve a relatively comparable framework for the statistical presentation of company accounts. Currently, as BACH recognizes, this new database includes comparable information on corporate financial statements and 29 economical-financial ratios aggregated by sectors and by firm size categories for 9 European countries (Austria, Belgium, Czech Republic, France, Germany, Italy, Poland, Portugal, and Spain). Although, this database has some limitations, "the Bach database is the most reliable source of available data containing balance sheet and profit and loss data for European companies" (EBA, 2012).

Given the importance of manufacturing for all of the countries, and because it is the sector that is covered the best by the database used, the study focuses on manufacturing sector. Those countries for which the database provides comprehensive information for manufacturing companies, broken down by firm size, for the entire series of 13 consecutive years (2000-12) were selected for the analysis. More specifically, the database provides complete information for six countries: Belgium, France, Germany, Italy, Portugal and Spain. The coverage of the manufacturing sector of these countries is shown in Table 1.

TABLE 1

COVERAGE RATIO OF THE MANUFACTURING SECTOR BY COUNTRY

\begin{tabular}{|ccccccc|}
\hline Year & Belgium $^{\mathrm{a}}$ & France $^{\mathrm{a}}$ & Germany $^{\mathrm{b}}$ & Italy $^{\mathrm{b}}$ & Portugal $^{\mathrm{b}}$ & Spain $^{\mathrm{a}}$ \\
\hline 2000 & 99.1 & n.a. & 79.4 & 76.0 & 69.8 & 37.5 \\
2012 & 100.0 & 87.3 & 74.3 & 81.6 & 97.7 & 59.4 \\
\hline
\end{tabular}

a The coverage rate is calculated in terms of number of employees, ${ }^{b}$ Coverage is measured on the basis of Turnover. n.a.: Not available

Source: Authors' elaboration on BACH-ESD Database.

Therefore, we extract two samples directly from the BACH database, one which compiles information on SMEs and another with information on large companies $^{2}$. The distribution by size of the manufacturing firms in the samples is presented in Table 2 .

\section{Evolution Of Performance: Descriptive Analysis}

This section presents a brief descriptive analysis of the evolution of the profits for each one of the samples (SMEs and large firms).

2 Bach Database establishes that size class is based on the Recommendation of the European Commission, 6 May 2003 (2003/361/EC), which only takes into account the turnover. 
TABLE 2

DISTRIBUTION OF FIRMS BY SIZE IN THE SAMPLES

\begin{tabular}{|rcrrrrrr|}
\hline Year & Sample & Belgium & France & Germany & Italy & Portugal & Spain \\
\hline \multirow{4}{*}{2000} & All firms & 20,691 & 38,130 & 1,0885 & 18,139 & 5,717 & 29,608 \\
& SMEs (\%) & 97.8 & 95.2 & 85.9 & 89.3 & 97.5 & 98.8 \\
& Large (\%) & 2.2 & 4.8 & 14.1 & 10.7 & 2.5 & 1.2 \\
\hline \multirow{4}{*}{2012} & All firms & 22,030 & 35,218 & 9,605 & 19,716 & 38,853 & 21,174 \\
& SMEs (\%) & 97.4 & 94.3 & 79.8 & 88.8 & 99.5 & 97.8 \\
& Large (\%) & 2.6 & 5.7 & 20.2 & 11.2 & 0.5 & 2.2 \\
\hline \multirow{2}{*}{2000} & Employees & 556,189 & $2,917,979$ & $2,881,661$ & $2,051,768$ & 422,942 & 855,276 \\
& SMEs (\%) & 49.8 & 49.2 & 22.5 & 48.6 & 72.1 & 58.5 \\
& Large (\%) & 50.2 & 50.8 & 77.5 & 51.4 & 27.7 & 41.5 \\
\hline \multirow{2}{*}{2012} & Employees & 453,885 & $2,411,256$ & $2,154,354$ & $1,864,006$ & 591,078 & 575,545 \\
& SMEs (\%) & 45.3 & 43.8 & n.a. & 48.1 & 85.0 & 44.5 \\
& Large (\%) & 54.7 & 56.2 & n.a. & 51.9 & 15.0 & 55.5 \\
\hline
\end{tabular}

n.a.: not available

Source: Authors' elaboration on BACH-ESD Database.

Profits are estimated by a profitability measure commonly used in the literature, and that is provided directly by the BACH / ESD database, return on assets (ROA), which is measured as the ratio of operating profit to total net assets. ROA can be broken down into profit margin (net operating profit / sales) and asset turnover ratio (sales / total assets), allowing additional information to be obtained regarding what determines the profitability of the companies.

$$
R O A=\frac{\text { Net Operating Profit }}{\text { Total Assets }}=\frac{\text { Net Operating Profit }}{\text { Sales }} \times \frac{\text { Sales }}{\text { Total Assets }}
$$

The database provides the weighted average of these ratios and also their quartiles. The value of the weighted average is influenced by the largest companies in each category and is biased by annual changes in the composition of the samples of each country. It is therefore more appropriate to use the median (or second quartile) of each of the ratios to perform a temporal analysis.

The following figures show the evolution of the median of each of these ratios for the different countries in each of the samples. Specifically, Figure 1 shows the evolution of ROA for the sample of large firms and Figure 2 for the sample of SMEs.

The evolution of the ROA shows, firstly, that throughout the period under consideration the large firms as a whole show higher levels of profitability than the SMEs and secondly, inter-country differences are smaller among the group of large enterprises.

In the years 2008 and 2009 there is a significant drop in the profitability of the companies in the different countries, for both SMEs and large firms. From the year 2009 on, the road to profitability shows a certain, although unstable, recovery due to the new falls in profits, especially in 2012. 


\section{FIGURE 1}

ROA TREND OF THE LARGE COMPANIES (2000-12)

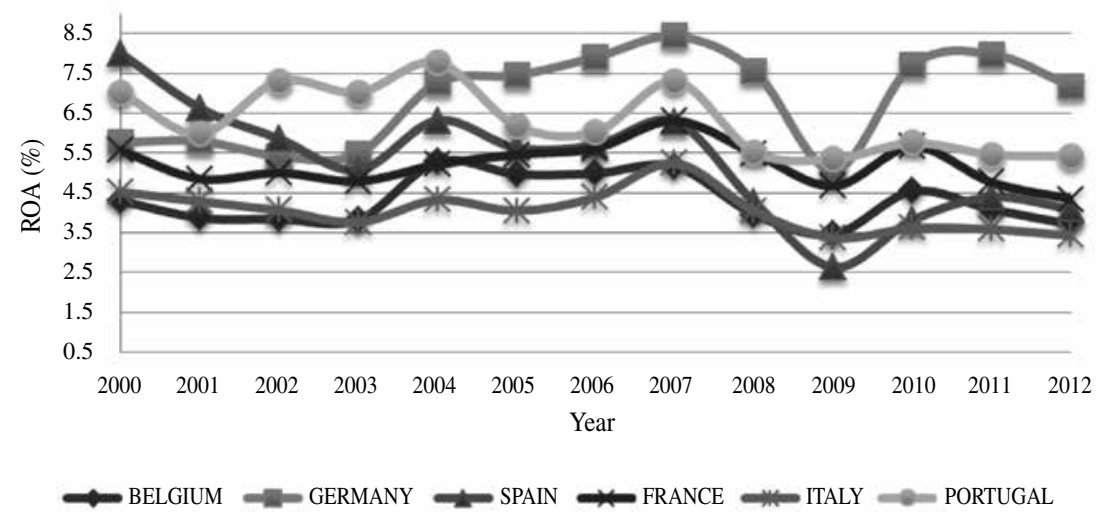

Source: Authors' elaboration on BACH-ESD Database.

FIGURE 2

ROA TREND OF THE SME COMPANIES (2000-12)

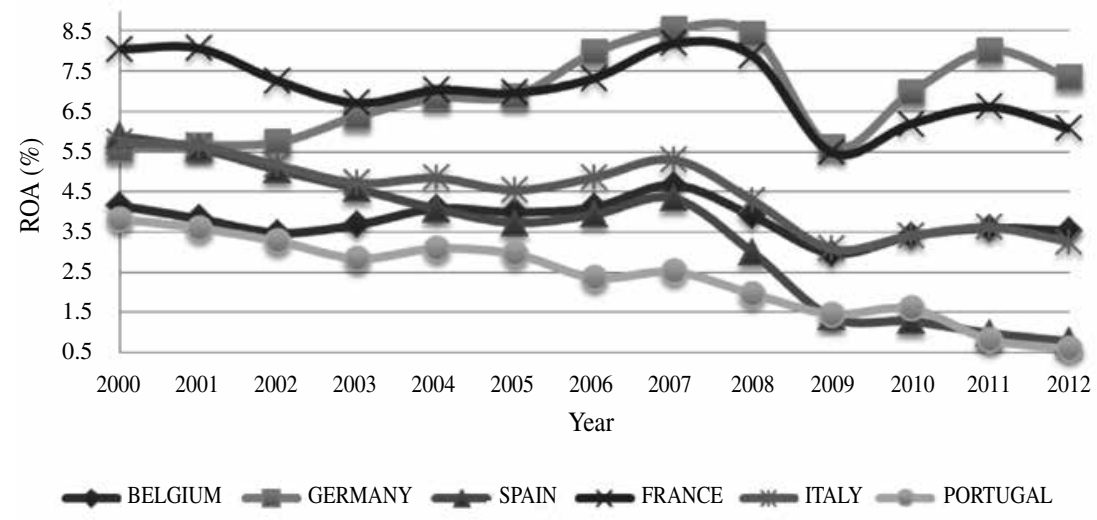

Source: Authors' elaboration on BACH-ESD Database.

Among the SMEs, the crisis appears to have widened the differences between countries, positioning Germany and France at the top, followed by Belgium and Italy with much lower levels of profitability, and at the lower end, Spain and Portugal.

Among large companies the trend seems to indicate a convergence of the profitability among the large firms of the different countries, with the exception of Germany which is situated significantly above the rest. 
FIGURE 3

PROFIT MARGIN TREND OF THE LARGE COMPANIES (2000-12)

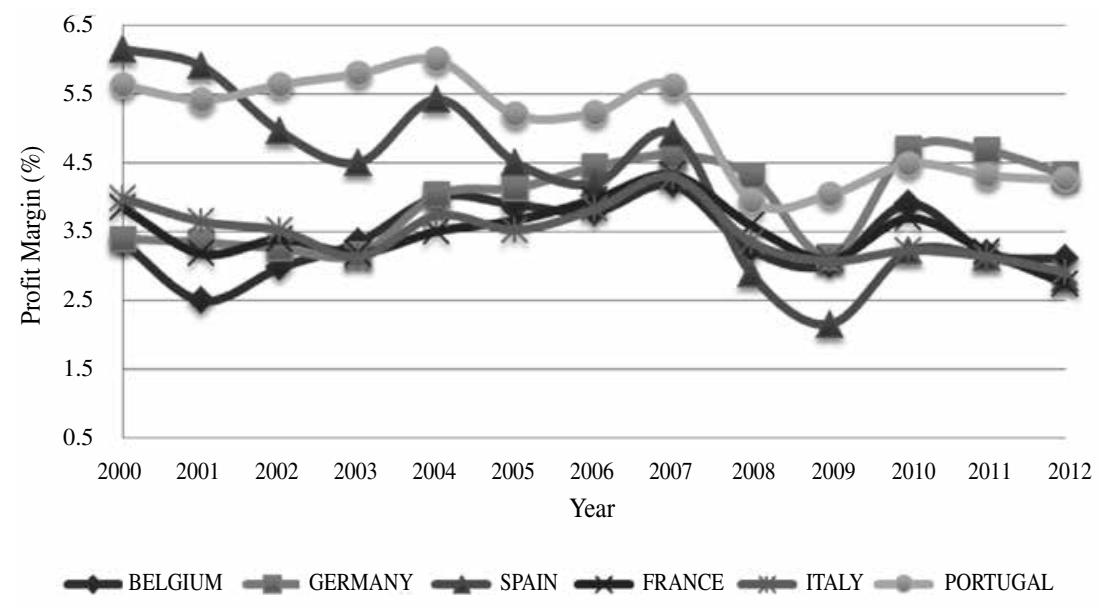

Source: Authors' elaboration on BACH-ESD Database.

FIGURE 4

PROFIT MARGIN TREND OF THE SME COMPANIES (2000-12)

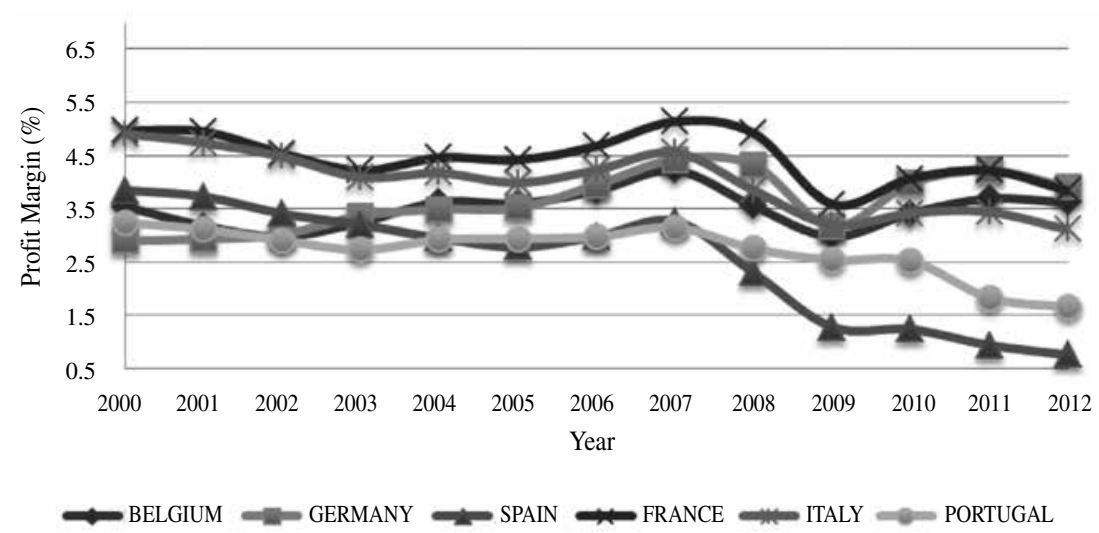

Source: Authors' elaboration on BACH-ESD Database.

With regards to the evolution of profit margins over time, inter-country differences appear to have diminished among the large firms (Figure 3) and increased among SMEs (Figure 4).

At the beginning of the period there were significant differences among the large companies and initially Spanish and Portuguese companies had the highest profit margins. While the crisis has caused a significant reduction in profit 
margins in all of the countries, the case of large Spanish companies is especially noteworthy; in 2009 their margins were the lowest of all of the countries analyzed.

The profit margins of the SMEs in Portugal, and especially in Spain, declined from 2007 on, situating themselves at levels lower than those of other countries. The downward trend continued for Portugal and Spain during the following years, unlike the other countries in the sample which showed signs of recovery in 2010 and 2011, although in 2012 these disappeared as profit margins dropped in all countries.

Figure 5 and 6 shows the temporal evolution of the asset turnover ratio, which also reveals how, at the end of the period, the inter-country differences within the group of SMEs have increased (Figure 6). The prominent position

FIGURE 5

ASSET TURNOVER RATIO TREND OF THE LARGE COMPANIES (2000-12)

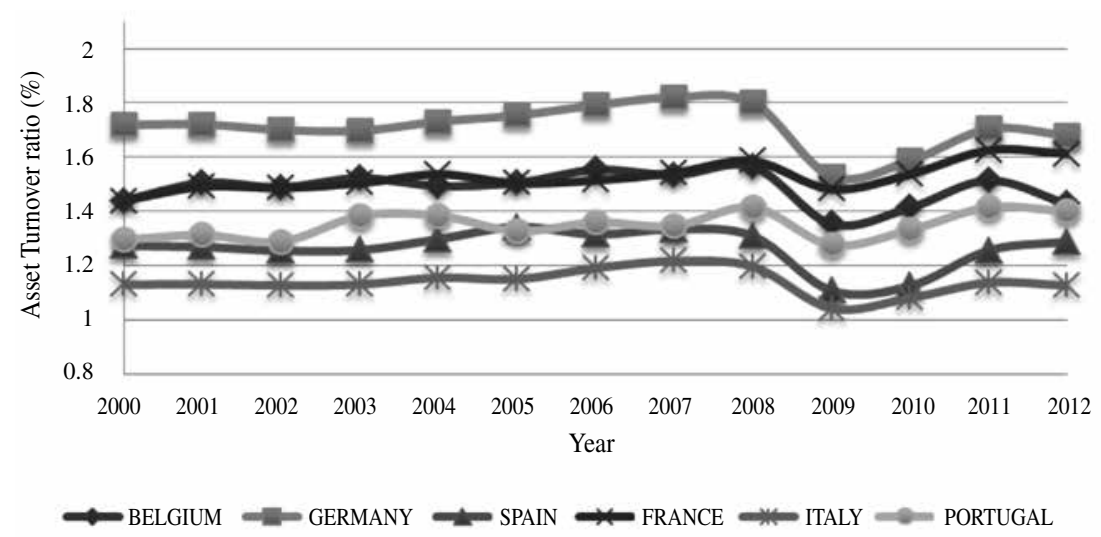

Source: Authors' elaboration on BACH-ESD Database.

FIGURE 6

ASSET TURNOVER RATIO TREND OF THE SME COMPANIES (2000-12)

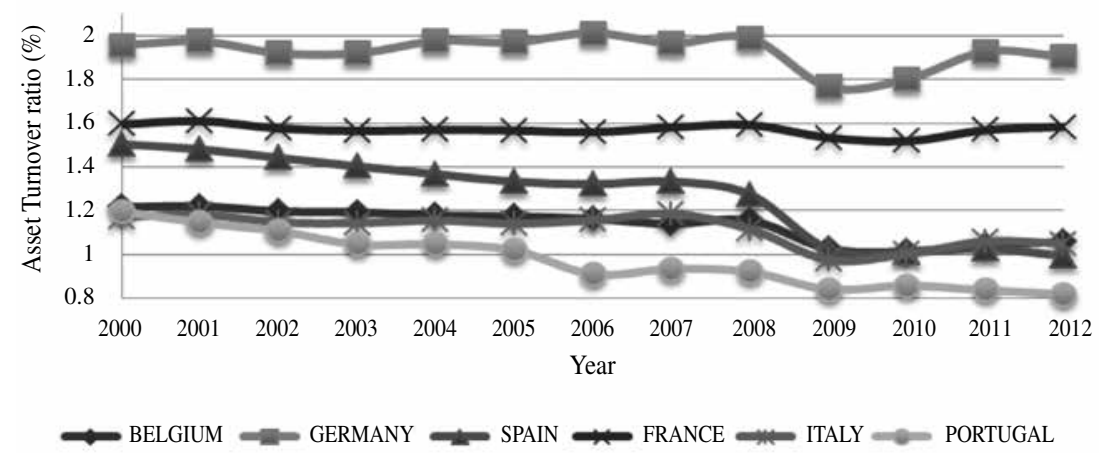

Source: Authors' elaboration on BACH-ESD Database. 
sustained by the German companies throughout the entire period, for both the group of large firms (Figure 5) as for the SMEs, should be noted.

From the previous descriptive analysis performed, some initial results are obtained that are worthy of mention. Throughout the period under review, and particularly from the crisis of 2008-09 onward, the differences among the SMEs from the different countries analyzed have increased, both in terms of profitability (ROA), as for its two components (profit margin and asset turnover ratio). More specifically, the Spanish and Portuguese SMEs are suffering the impact of the crisis most severely, which is primarily affecting their profit margins, which have declined significantly.

Large Spanish companies, together with French SMEs, were the most profitable at the beginning of the period. Their superior performance was driven primarily by a higher profit margin. However at the end of the period it is the German companies, both large firms and SMEs that show the highest values for both overall profitability, as for its two components; profit margin and asset turnover. Throughout the period of the study the German companies are the ones that have consistently held the top position in asset turnover in both groups of companies. This, together with the favourable evolution of their profit margins, has led them to occupy the first position in terms of profitability.

\section{ReSEARCh DeSign}

This section presents the theoretical convergence model as well as the measurement of the variables and the methodology used to achieve the objectives of the study.

\subsection{Theoretical Convergence Model}

To achieve the first objective, to study the process of convergence of long-run corporate profits of European SMEs and large companies, a model commonly used in the literature known as the "Partial Adjustment Model" was used. This model is based on the fundamental assumption that the entry and departure of firms from a specific market influences the excess profits obtained by the firms operating in that market (Geroski, 1985 and Geroski and Jacquemin, 1988).

Thus,

$$
\Pi_{\mathrm{jt}}=\mathrm{f}\left(\mathrm{E}_{\mathrm{t}}\right)
$$

Where $\prod_{j t}$ is the excess profit earned in period t for the company $j$ and $E_{t}$, as indicated by Geroski (1990), must be interpreted in the broad sense, thereby including both the threats of new entries by firms as well as the entries and departures of firms.

If the returns obtained by the firms currently operating in the market are above average, other firms, attracted by those returns, will attempt to enter, or will enter, the market in question. Conversely, if the returns obtained by the firms are below average, the opposite will occur and firms will leave the market. Given that these processes require a certain amount of time, it is assumed that the 
entries and departures of a sector during the period $t$ are a function of the excess profits (positive or negative) obtained in the given sector during the period $\mathrm{t}-1$.

$$
\mathrm{E}_{\mathrm{t}}=\mathrm{g}\left(\Pi_{\mathrm{jt}-1}\right)
$$

Plugging (3) into (2), yields

$$
\Pi_{\mathrm{jt}}=\mathrm{f}\left(\mathrm{g}\left(\Pi_{\mathrm{jt}-1}\right)\right)
$$

Assuming that $\mathrm{f}$ and $\mathrm{g}$ are linear first-order polynomial functions, the following model is obtained:

$$
\Pi_{\mathrm{jt}}=\alpha_{\mathrm{j}}+\lambda_{\mathrm{j}} \Pi_{\mathrm{jt}-1}+\varepsilon_{\mathrm{jt}}
$$

The existence of long-run convergence implies that differences between $\prod_{\mathrm{jt}}$ and $\prod_{\mathrm{jt}-1}$ diminish over time and can be analyzed through the parameter $\lambda_{\mathrm{j}}$. An estimated value of $0<\lambda_{j}<1$, implies a gentle process of convergence towards the value in the long run. An estimated value of $\lambda_{j}>1$ implies that results increase indefinitely, therefore there would be no convergence in the long run. On the other hand, values of $\lambda_{j}<0$ give rise to continuous fluctuations in returns, which could either increase (if $\lambda_{j}<-1$ ) or decrease (if $\lambda_{j}>-1$ ). Therefore, convergence would only occur in the latter case. Finally, a value of $\lambda_{j}$ equal to zero would imply that convergence has already occurred.

Ultimately, long-run convergence would imply that the estimated value of coefficient $\lambda_{\mathrm{j}}$ is situated between minus one and one. If the condition for convergence is met, then the absolute value of $\lambda_{j}$ is an indicator of the speed of the process, therefore a high absolute value for $\lambda_{\mathrm{j}}$ implies a slower convergence toward the profit in the long run.

Furthermore, if convergence does occur, the mean value of the long-run profits $\left(\mathrm{PLR}_{\mathrm{j}}\right)$ can be obtained from the following expression:

$$
\operatorname{PLR}_{j}=\alpha_{j} /\left(1-\lambda_{j}\right)
$$

From the long-run convergence values obtained for each unit of analysis $\mathrm{j}$ it is possible to determine the extent to which their long-run profits tend to even out over time or, on the contrary, to remain at levels that differ substantially from one another. Therefore, if the convergence value of unit $\mathrm{j}$ is close to zero it is because $\mathrm{j}$ does not have a significant advantage or disadvantage with respect to other units of analysis.

\subsection{Profit Measurement}

Return on Assets (ROA) is used as a measure of return and is calculated as Net Operating Profit divided by Total Assets. The data is provided by the BACH/ 
ESD database and is available by firm size categories (i.e., for SMEs and large firms) for each country.

Given that the competitive process is motivated by above or below average profit levels, the ROA was standardized following Goddard and Wilson (1996). The deviation from the average ROA for the group of similar size (SME or large) manufacturing firms of all the countries in the samples was then calculated. Moreover, the standardization of this measure, as Goddard and Wilson (1996) point out, allows the effects on profitability of the cyclical factors operating at the aggregate level to be eliminated.

$$
\Pi_{\mathrm{jt}}=\mathrm{ROA}_{\mathrm{jt}}-1 / \mathrm{n} \sum_{\mathrm{j}=1}^{\mathrm{n}} \mathrm{ROA}_{\mathrm{jt}}
$$

$\prod_{\mathrm{jt}}:$ The standardized ROA of the representative firm ${ }^{3}$ of the manufacturing sector of country $\mathrm{j}$ in period $\mathrm{t}$.

$\mathrm{ROA}_{\mathrm{jt}}$ : The ROA of the firm that is representative of the manufacturing sector of country $\mathrm{j}$ in period $\mathrm{t}$.

This is done for every country included in each of the two samples classified by firm size (SMEs or large firms).

\subsection{Methodology}

The convergence model shown in equation (5) is applied to the manufacturing sector of each of the six countries and for each of the samples (SMEs versus large firms).

$$
\Pi_{\mathrm{jt}}=\alpha_{\mathrm{j}}+\lambda_{\mathrm{j}} \Pi_{\mathrm{jt}-1}+\varepsilon_{\mathrm{jt}}
$$

Where $\mathrm{j}=$ Belgium, France, Germany, Italy, Portugal and Spain, and $\mathrm{t}=$ 2000-12.

The dependent variable in each of the estimated equations is the standardized ROA in period $t$ of the firm that is representative of the manufacturing sector in each country. For each country, the model is estimated for both samples (SMEs and large firms).

These dependent variables are variables of the same kind, and are related due to the interdependence of the countries. In other words, they are related to each other at every moment in time through their stochastic components, with each variable containing relevant information concerning the evolution of the others. We therefore suggest that it would be appropriate to process these equations simultaneously, since the combined estimation of their values is more effective than processing each of them individually in isolation. Taking into account these considerations, the Seemingly Unrelated Regressions Equations (SURE) Model estimation procedure was applied for each of the samples classified by firm size.

3 We consider the representative firm of each country that which has a ROA value equal to the median that is provided by the database. Advantages of this measure are that the values of very large enterprises and other extreme values do not bias the results and that the median value is less influenced by annual changes in the composition of the samples of each country. Therefore this is a more adequate measure to analyze the long-run tendency of the results. 
To achieve the second of the proposed objectives, determine the impact of the current financial crisis on the process of convergence of business results, we use a threshold estimation to investigate whether the equations that describe the long-run profit path have been modified during the period analyzed. Following Hansen (2000), the following threshold regressions are estimated:

$$
\begin{array}{ll}
\Pi_{j t}=\alpha_{j}^{1}+\lambda_{j}^{1} \Pi_{j t-1}+\varepsilon_{j t} & \text { if Year } \leq \gamma \\
\Pi_{j t}=\alpha_{j}^{2}+\lambda_{j}^{2} \Pi_{j t-1}+\varepsilon_{j t} & \text { if Year }>\gamma
\end{array}
$$

where $\gamma$ is the endogenously determined sample threshold that divides the observations into two groups. The rest of the coefficients are similar to those defined in equation (5).

The estimation of equation (8) involves two main steps. First, the endogenously determined sample split threshold value is estimated by minimizing the sum of mean squared errors. Second, to test whether the threshold estimated is statistically significant, the bootstrap methodology is used. If it is significant, it would indicate that the equation that represents the path of the profits differs by sub-periods.

\section{The Convergence Process And The Impact Of The Crisis: Results}

The results of the estimation of the equations corresponding to the Partial Adjustment Model for the manufacturing sector of each of the six countries under consideration appear in Table 3. Table 3 shows the standardized ROA value for each of the countries and for each of the samples (SMEs and large FIRMS ) for the first period of the series $\left(\prod_{\mathrm{j} 2000}\right)$, the parameters estimated for the model $\left(\alpha_{\mathrm{j}}, \lambda \mathrm{j}\right)$, the long term convergence value of the excess profitability obtained by them $\left(\mathrm{PLR}_{\mathrm{j}}\right)$ and the adjusted $\mathrm{R}^{2}\left(\operatorname{adj} . \mathrm{R}^{2}\right)$.

The model used to describe the competitive process explains the evolution of the profitability for most of the countries analyzed except for French SMEs.

For the other countries the goodness of fit is for the most part high and the adjusted $\mathrm{R}^{2}$ varies from a low of 2.71 per cent in the case of large Italian companies, to a maximum of 93.78 per cent for Spanish SMEs.

In light of the above we obtain the following results for the convergence of long-run profits of European manufacturing companies.

The condition for convergence $(-1<\lambda j<1)$ is met for all countries when the sample of large firms is analyzed. This condition is also met in the majority of the countries for the sample of SMEs, with the exception of Belgium ${ }^{4}$. The estimated values of $\lambda_{\mathrm{j}}$ are somewhat higher than those reported in several earlier European manufacturing studies, such as those of Geroski and Jacquemin (1988) y Goddard et al. (2005), which obtained values in the area of 0.5. These

$4 \quad$ In this case, the $\lambda$ parameter value slightly greater than one observed, rather than indicating a lack of convergence, could be interpreted as the process of convergence for Belgium being very slow. 


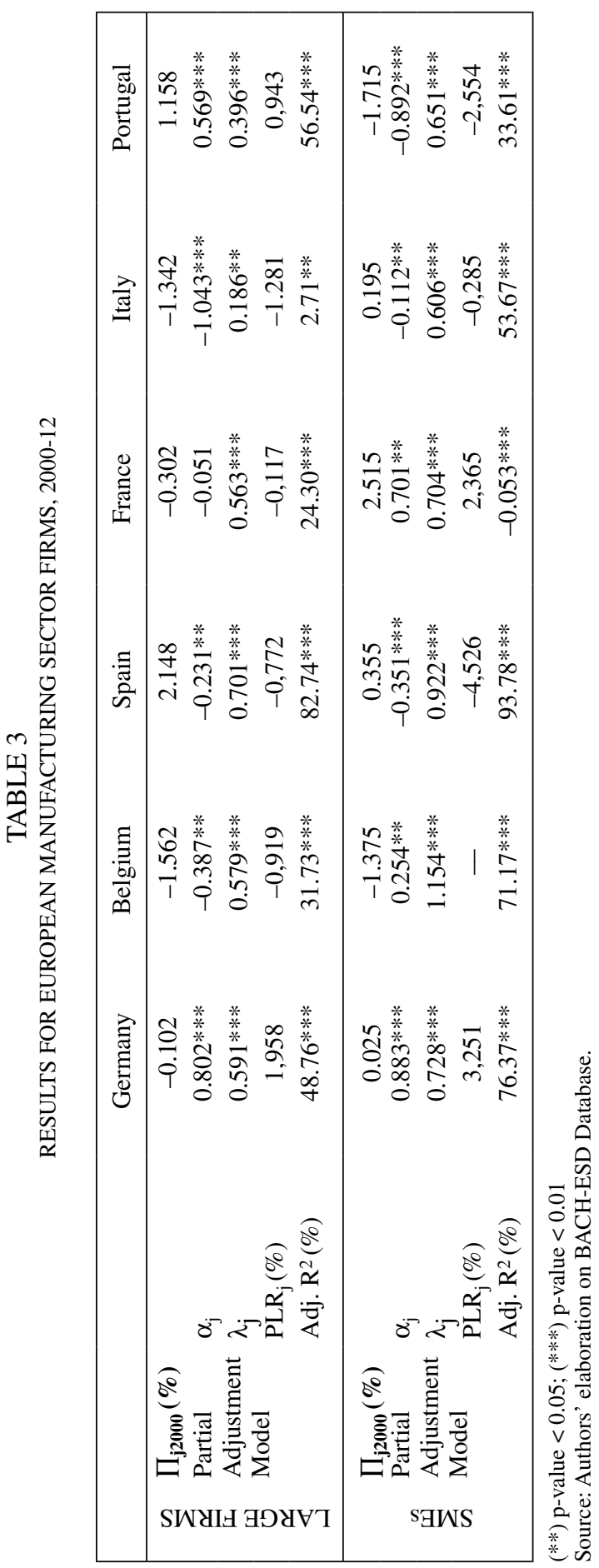


values suggest a slow convergence process in which the extraordinary profits tend to persist from year to year, eroding slowly over time as a consequence of the competitive forces.

With regards to the differences observed in relation to the size of the firms, it is observed that the variability of the rate of the convergence process $\left(\lambda_{j}\right)$ for the European countries analyzed is slightly higher among the SMEs than among the large companies. In addition, the $\lambda_{\mathrm{j}}$ values are generally lower (and closer to those observed in other research) in the sample of large firms than in the SMEs, suggesting that the pace of convergence is faster in the first sample (large firms), or in other words, greater profit persistence is observed in the SMEs.

The values towards which the profits of the companies converge $\left(\mathrm{PLR}_{\mathrm{j}}\right)$, are more homogeneous among the large firms than among the SMEs. Nevertheless, Germany stands out for its high convergence values, both for the sample of SMEs as for the large enterprises, demonstrating that the favourable situation of this country observed today appears to persist over the long run.

Finally, the difference between the countries situated at the extremes in the period 2000 (Spain versus Belgium) is 3.71 percentage points for the large companies, however the difference is reduced to 3.24 points (Germany versus Italy) when the long-run convergence values are considered. With regard to the SMEs, the initial difference starts at 4.23 points (France versus Portugal), but increases to 7.77 when convergence values are considered (Germany versus Spain).

Therefore, although the results should be treated with the necessary caution derived, among other things, from the limitations of the accounting information, the evidence suggests that the inter-country competitive process is far from perfect. These results are consistent with those obtained by Goddard et al. (2005) who analyze the manufacturing and service sectors of five European countries (Belgium, France, Italy, Spain and UK). They conclude that despite that the formation of the European Single Market has reduced barriers to entry and exit and has intensified competition among firms from different countries, competitive forces are not sufficiently strong to eliminate all abnormal profits. Hirsch and Gschwandtner (2013) obtain similar results when analyzing profit persistence in the European food industry. Therefore, and as indicated by Geroski and Jacquemin (1988), country, as well as firm and industry specific factors explain the persistence of profits in the long run. The performance of firms may still derive from factors specific to the country in which each firm is located.

From the results obtained it follows, however, that the differentiation by firm size is relevant in the analysis of the competitive process. The inter-country competitive process works better among large firms than among small and medium enterprises in the different countries. The differences between large firms and SMEs could be justified because the large firms tend to be more internationalized and operate in a wider geographical scope, therefore they are less dependent on their domestic markets and less sensitive to changes in them. On the contrary, evidence shows that only 2\% of the SMEs of the 27 Member States of the European Union have made Foreign Direct Investments and only $25 \%$ are exporters (European Commission, 2010). The SMEs face greater difficulties for their internationalization such as less access to informa- 
tion (Buckley, 1989; Child y Hsieh, 2014); financial restrictions and scarcity of resources (Bellone et al., 2010), experience, workforce training and the ability of the executives to evaluate opportunities (Chetty et al., 2006), among others. Therefore, the majority of the SMEs are dependent on their domestic market and the convergence process is slower.

Regarding the impact of the crisis on the convergence process, although it would be good to replicate the threshold estimations with a longer time series, the results suggest that the crisis has not changed the relative tendency of the results obtained by the large companies in the different countries since the threshold values estimated are not statistically significant.

However, the results for SMEs indicate significant sample breaks for France $(\gamma=2007)$ and Italy $(\gamma=2006)$ (Table 4$)$. In both cases, the values toward which the profits of the companies converge $\left(\mathrm{PLR}_{\mathrm{j}}\right)$ and the speed of the convergence process change before and after the endogenously estimated threshold values $(\gamma)$. More specifically, the lambdas estimated become negative after the crisis indicating continuous and decreasing fluctuations in returns and therefore, greater instability.

However, it will be necessary to wait a few years and have data for a longer period of time to assess whether the competitive process intensifies after this economic collapse and if, as a result, the profits of companies in the different countries tend toward greater equalization.

\section{Conclusions}

In recent years, companies in all of the economies of the world have been affected by an unprecedented economic crisis, but it has been the companies in the more developed countries which have suffered the most.

The crisis has caused high levels of instability and uncertainty and has resulted in numerous companies being expelled from the market, and a significant drop in the profits for the survivors.

Faced with this evidence, this study addresses a twofold objective. Firstly, to study whether there is a process of convergence of the long-run profits of the companies and secondly, whether this process has been affected by the crisis. The analysis is performed within the scope of the European Union which, as a result of its economic integration, makes it difficult for the individual countries to establish entry barriers to protect their businesses. Furthermore, given the differences that exist between SMEs on one hand, and large companies on the other, this convergence process was analyzed differentiating between these two groups of firms.

Although there is extensive literature on the convergence of profits at an international level, primarily within the framework of industrial economics, to our knowledge there are no studies that address the objectives proposed. We used a model proposed in the literature (Partial Adjustment Model) and applied it to the manufacturing sector of six European countries, differentiating between SMEs and large firms, over a period of 13 years (2000-12). The information was obtained from the European database BACH / ESD. 


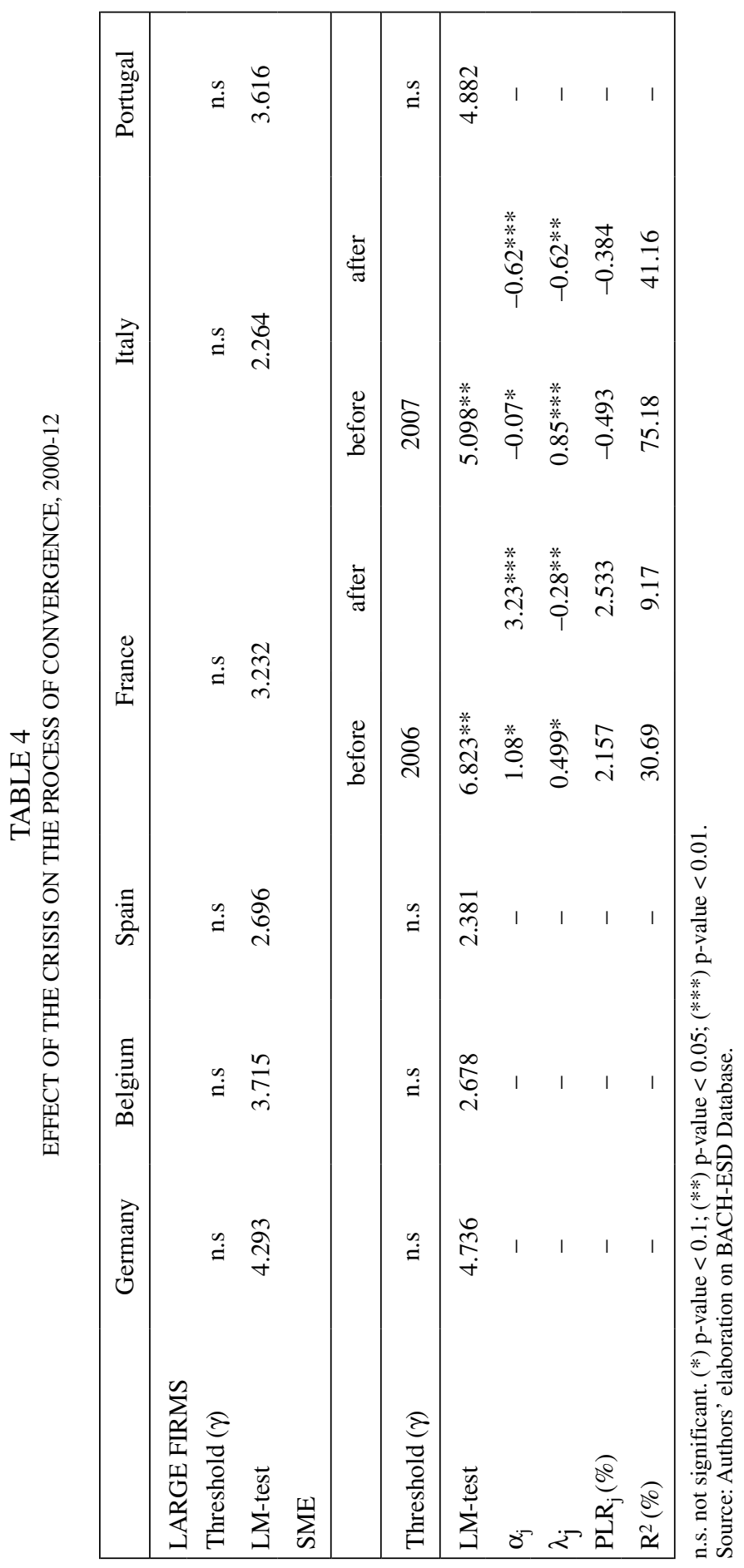


Prior to the application of the proposed model, we performed a descriptive analysis of the evolution of the return on assets (ROA) and its components, which yielded some interesting preliminary results.

The severe impact of the crisis (2008-09) on the companies' ROA is confirmed, regardless of their size. The large companies are the ones that earn higher returns throughout the entire period but the inter-country differences among them are smaller and some convergence among them is observed. However, the crisis appears to have increased the differences in the profitability of SMEs among the different countries. When its components (profit margin and asset turnover) are analyzed, the sharp fall in profit margins for both samples and the increase in differences in the SMEs' asset turnover among the countries is especially striking.

These initial results are confirmed when we analyze the process of convergence of long-run profits. The results indicate that, except for the case of Belgian SMEs, it is possible to predict a result at which the companies of the different countries will converge in the long run. Convergence values however, vary among countries, which indicates that the competitive process is far from perfect since if this were the case, the long-run standardized results would tend to zero in all the countries. In any case and considering the differences observed due to size, the results indicate that the inter-country competitive process works better in the case of large firms, as this sample progresses at a faster pace and shows greater homogeneity in the process of convergence of profits among the different countries, and also toward homogeneous values among countries, than in the case of SMEs.

In this process, Germany stands out for its high convergence values for both samples, SMEs and large companies, underscoring that the current favourable position of this country appears to persist over the long run.

Finally, we have also found that although the crisis has provoked a general decrease of the performance for the manufacturing sector for all countries, the crisis only causes a significant sample break for French and Italian SMEs, where it is observed that after the estimated thresholds, economic instability increases.

Having said this, the results obtained should be interpreted with caution and are not generalizable to all economic activities given that our sample only considers the manufacturing sector, the amount of data available is limited, and the data is not fully harmonized. Although we acknowledge these limitations of the database, we agree with $\mathrm{BACH}$ when it says that it can provide relevant information on the state and evolution of the profitability of the sector. Therefore our study provides insight into the state of the issue.

Moreover, research providing an initial approach to the study of the process of profit convergence for European companies while differentiating between SMEs and large companies, and the impact of the current economic crisis on this process, is current and of great interest. Furthermore, no studies on this subject have been found to date. For these reasons, additional research is necessary. Some possible lines of research could include analyzing other economic sectors, or other economic regions (e.g. MERCOSUR or NAFTA); or given the scarcity of homogeneous data across different countries, it would be interesting to study the convergence process within a specific country. 


\section{REFERENCES}

Archibugi, D. and Filippetti, A. (2011). "Is the Economic Crisis Impairing Convergence in Innovation Performance across Europe?", Journal of Common Markets Studies -JCMS-, Vol. 49, N ${ }^{\circ}$ 6, pp. 1153-1182.

BACH-ESD Database (2013). Banco de España, Banco de Portugal, Banque de France, National Bank of Belgium, National Bank of Poland, Central Bureau voor de Statistiek (the Netherlands), Centrale dei Bilanci - Cerved srl, Deutsche Bundesbank, Oesterreichische Nationalbank.

Bellone, F.; Musso, P.; Nesta, L. and Schiavo, S. (2010). "Financial Constraints and Firm Export Behaviour". World Economy, №33, pp. 347-373. doi: 10.1111/j.1467-9701.2010.01259.

Buckley, P.J. (1989). "Foreign direct investment by small and medium sized enterprises: The theoretical background", Small Business Economics, Vol. 1 (2), pp. 89-100.

Chetty, S.; Eriksson, K., and Lindbergh, J. (2006). "The effect of specificity of experience on a firm's perceived importance of institutional knowledge in an ongoing business", Journal of International Business Studies, Vol. 37 (5), pp. 699-712.

Child, J. and Hsieh, L. (2014). "Decision mode, information and network attachment in the internationalization of SMEs: A configurational and contingency analysis", Journal of World Business, in press, DOI: 10.1016/j.jwb.2013.12.012.

Eklund, J.E. and Wiberg, D. (2007). "Persistence of Profits and the systematic search for knowledge: R\&D links to Firm Above-Norm Profits". CESIS Electronic Working Paper Series, $N^{\circ} 85$.

Espitia, M. and Salas, V. (1989). "Beneficios a Largo Plazo de las Empresas Españolas". Papeles de Economía Española, № 39, pp. 397-413.

EBA (2012). Assessment of SME proposal for CRD IV/CRR. September 2012. Available at http://www.eba.europa.eu/documents/10180/16148/EBASME-Report.pdf

European Commission (2010). Internationalisation of European SMEs. Published by Entrepreneurship Unit, European Commission.

European Commission (2012). "Annual Report on EU Small and Medium sized Enterprises 2012". Available at "http://ec.europa.eu/enterprise/policies/sme/ facts-figures-analysis/performance-review/files/supporting-documents/2012/ annual-report_en.pdf".

Geroski, P. (1985). "The persistence of profits: Some methodological remarks on measurement and explanation", Discussion paper IIM/IP 85-22, International Institute of Management, Berlin, 1985.

Geroski, P. (1990). "Modelling Persistent Profitability", in Mueller, D.C. (ed.), The Dynamics of Company Profits: an International Comparison (Cambridge: Cambridge University Press).

Geroski, P. and Jacquemin, A. (1988). "The Persistence of Profits: A European Comparison". The Economic Journal, $\mathrm{N}^{\circ}$ 98, pp. 375-389.

Goddard, J.A. and Wilson, J.O.S (1996). "Persistence of Profits for UK Manufacturing and Service Sector Firms". The Service Industries Journal, Vol. 16, April, pp. 105-107. 
Goddard, J.A.; Tavakoli, M. and Wilson, J.O.S. (2005). "Determinants of profitability in European manufacturing and services: evidence from a dynamic panel model", Applied Financial Economics, 15: 18, pp. 1269-1282.

Hansen, B.E. (2000). "Sample splitting and threshold estimation", Econometrica Vol. 68, pp. 575-603.

Hirsch, S. and Gschwandtner, A. (2013). "Profit persistence in the food industry: evidence from five European countries", European Review of Agricultural Economics, Vol. 40 (5), pp. 741-759.

Jenny, F. and Weber, A. P. (1990). "The persistence of profits in France", in Mueller, D.C. (ed.), The Dynamics of Company Profits: an International Comparison (Cambridge: Cambridge University Press).

Leonardi, R. (1995). Convergence, Cohesion and Integration in the European Union (London: McMillan).

Schohl, F. (1990). "Persistence of Profits in the Long Run. A Critical Extension of Some Recent Findings". International Journal of Industrial Organization, $\mathrm{N}^{\mathrm{o}}$ 8, pp. 385-404. 
